\title{
Evaluation and Testing of In Vitro Labeled Technetium Tc-99m Red Blood Cells in Two Animal Models for Neonatal RBC Volume Determinations
}

\author{
J. WILLIAM DIRKSEN, MERTON A. QUAIFE, ${ }^{(11)}$ CHARLES L. PAXSON, JR., AND \\ TERRENCE P. BARTON \\ University of Nebraska Medical Center, Omaha, Nebraska, USA
}

\begin{abstract}
Summary
The present study was designed to evaluate the red blood cell ( $R B C)$ radiolabeling technique utilizing the short half-lived radionuclide technetium- $99 \mathrm{~m}$ and to compare the results with the wellrecognized standard chromium-51 method. The procedure was evaluated in a canine and a newborn lamb model utilizing dual radionuclide labeling and counting techniques. With the express purpose of providing a significant radiation dose reduction, the procedure presented was adapted for utilization in a neonatal patient population. Statistical analysis of the data revealed that there was no significant difference in the radiolabeling efficiency for the two methods (Cr-51, 86.6\%; Tc-99m, 92.4\%). Assessment of the in vivo stability for technetium-99m RBCs showed that less than a $4 \%$ loss of radiolabel from the RBC was seen in a 4hr time span in the canine model (15 min, $90.5 \% ; 2 \mathrm{hr}, 88.9 \% ; 4 \mathrm{hr}, 86.6 \%$ ) when compared to the 15 min equilibrium sample.

Evaluation of newborn lamb RBC volumes showed that the technetium- $99 \mathrm{~m}$ RBC volume did not significantly differ from the chromium-51 labeling technique (Cr-51, $24.0 \mathrm{ml} / \mathrm{kg}$; Tc-99m, 23.2 $\mathrm{ml} / \mathrm{kg}$ ). Summarization of the whole-body radiation dose showed that greater than a 30-fold reduction in absorbed dose was achieved in the newborn (Cr-51, 30.0 mrad; Tc-99m, $0.9 \mathrm{mrad})$. The modified procedure presented for the radiolabeling of the $\mathrm{RBC}$ with the short half-lived radionuclide technetium- $99 \mathrm{~m}$ provides a technique comparable to the utilized standard chromium-51 RBC method, yet with a large reduction in absorbed radiation dose. This procedure is presented as a superior technique for the determination of pediatric RBC volumes.
\end{abstract}

\section{Speculation}

Demonstration of the efficacy of radionuclide dilution techniques in two species (animal models) predicates for the application of this procedure in neonates. The accurate assessment of circulating red blood cell volume affords the neonatologist a unique management tool while accruing significant radiation dose reduction using the short half-lived technetium- $99 \mathrm{~m}$ rather than the standard chromium-51 technique.

Interest has been generated in contemporary medical practice for newer, and perhaps more novel, methods for applying radioactive tracer techniques. Routine procedures are commonly utilized in the assessment of the cardiovascular system using available short, half-lived radiopharmaceuticals. A number of such techniques have been advanced for the in vivo labeling of red blood cells (RBCs) with the radionuclide technetium $\left({ }^{99 \mathrm{~m}} \mathrm{Tc}\right)$ pertechnetate. Although these newer studies have provided a significant advance in functional imaging, the quantitative assessment of volume in the vascular compartment requires a return to classical radionuclide volume dilution techniques $(1,5,6)$.
The accurate assessment of blood volume and its constituent compartments is often of critical importance in the clinical management of a wide spectrum of disease manifestations. The interest of the authors was particularly drawn to the critical management problems of hypotensive preterm neonates and the potential value of direct quantitative assessment of the circulating vascular volume. Rather than continuing use of ratio studies, i.e., hemoglobin, hematocrit, and/or RBC values, which may mislead because of compartmental shifts in volume in pathophysiologic states, the application of standard radionuclide dilution techniques offers an attractive alternative. Its established role in circulating vascular volume management in adults predicates for a similar application in this patient population (2). Of the two major components of the circulating vasculature, i.e., plasma volume and red cell volume, the latter is generally considered to be vital in terms of management of tissue hypoxia/hypoxemia in the hypotensive state. Although the routine use of ${ }^{51} \mathrm{Cr}$-labeled RBCs has been a routine part of the nuclear medicine consultative armamentarium for many years, our continuing desire for radiation dose reduction concurrent with ensurance of accurate measurement suggested study of other radionuclide labels. The use of a short half-lived radionuclide would offer not only the potential for radiation dose reduction but also allow the administration of augmented levels of tracer, improving the statistical aspects of radiometric analysis and a reduction in time required for completion of the study (counting time). This serendipitous dual advantage appeared feasible if a rapid in vitro labeling technique could be developed using specimen volumes compatible with the patient population and ${ }^{99 \mathrm{~m}} \mathrm{Tc}$ pertechnetate labeling of RBCs.

To offer an acceptable alternate method for $\mathrm{RBC}$ volume determination, the technique must be shown to correlate with the classical ${ }^{51} \mathrm{Cr} \mathrm{RBC}$ technique as well as being adaptable to the reduced volumes necessary in dealing with preterm neonates. The purpose of this study was to apply a modification of the radioactive labeling technique of Subramanian (10) for the purpose of direct quantitation of preterm and term neonatal $R B C$ volumes and to validate this technique against the classical approach.

\section{MATERIALS AND METHODS}

\section{RADIOLABELING OF RBCS}

The labeling procedure described was carried out in sterile vacuum test tubes utilizing standard aseptic techniques. Immediately after the withdrawal of $4 \mathrm{ml}$ of heparinized venous whole blood, the sample was injected into a sterile vacuum test tube, Vacutainer, containing one $\mathrm{ml}$ of a $3.5 \%$ citric acid solution. After centrifugation, the supernatant was removed from the packed cells by withdrawal with a sterile spinal needle and disposable syringe. The packed cells were washed and resuspended in normal saline. After a short incubation period with a stannous (Sn II) chloride 
solution, 5 to $30 \mu \mathrm{Ci}$ of technetium pertechnetate were added and incubated for a final time. At this point, the RBCs were ready for reinjection. In vitro stability of the ${ }^{99 \mathrm{~m}} \mathrm{Tc}$ RBCs was determined by assessment of the bound-free ratio over time. Samples of the RBC were removed from the labeling container at timed intervals. The cellular and plasma compartments were separated to determine bound and unbound fractions and assayed radiometrically for $\mathrm{RBC}$ percent binding loss determinations.

\section{ANIMAL MODEL}

To assess the in vivo validity of ${ }^{99 \mathrm{~m}} \mathrm{Tc} \mathrm{RBC}$, as compared to ${ }^{51} \mathrm{Cr}$ cells, a total of 26 mongrel dogs were used to evaluate the labeling stability and reproducibility of the two methods. In addition to the canines utilized for testing of the radiolabeled RBCs, six newborn lambs were studied to establish this procedure in a second animal model as well as evaluating its use in the newborn.

Initially five canines were used, only as blood donors, in the developmental stages of the in vitro labeling technique. Eight dogs were injected with ${ }^{99 \mathrm{~m}} \mathrm{Tc}$ RBCs to test the in vivo stability of the technique. Four $\mathrm{ml}$ of whole blood were withdrawn from each animal and labeled in the prescribed manner. Aliquots from each preparation of cells were reinjected into the donor animal and venous whole blood samples were removed at $15 \mathrm{~min}, 2 \mathrm{hr}$, and $4 \mathrm{hr}$ postinjection. All samples were assayed and corrected for counts in the plasma. Radioactivity in the samples was expressed as percent bound in comparison to the 15 -min equilibrium, sample.

An additional 13 dogs were studied to make a comparative evaluation between ${ }^{99 \mathrm{~m}} \mathrm{Tc}$ and ${ }^{51} \mathrm{Cr} \mathrm{RBCs}$. Eight $\mathrm{ml}$ of venous whole blood were withdrawn from each dog and equally divided. One-half was labeled with technetium using the described method, whereas the other half was labeled with chromium using a standard method (4). Equal amounts of each RBC standard were mixed and reinjected. Venous samples were withdrawn at 15-min postinjection. The samples were assayed for ${ }^{99 \mathrm{~m}} \mathrm{Tc}$ and ${ }^{51} \mathrm{Cr}$ activity utilizing dual-pulse height radionuclide gamma counting techniques. $\mathrm{RBC}$ volume calculations were performed for each radionuclide, and the mean value obtained for each group was statistically compared utilizing a paired "Student's" $t$ test. In addition to $\mathrm{RBC}$ volume determination, the percentage of radiolabel injected in the standard, that was bound to the cells, was calculated in both procedures to determine percentage of binding for each.

To assess this procedure in a newborn animal model, the dual labeling procedure was repeated in six newborn lambs. Statistical analysis on the mean RBC volume, as determined for each radionuclide, was made to ascertain whether the values obtained by the technetium labeling technique compared favorably with those obtained from chromium labeled RBCs.

\section{RESULTS}

The in vitro stability of ${ }^{99 \mathrm{~m}} \mathrm{Tc} \mathrm{RBCs}$ was tested to determine the percentage loss of radioactive label. The ${ }^{99 \mathrm{~m}} \mathrm{Tc}$ labeled RBCs were found to be stable with less than $2 \%$ loss over a 6 -hr time period. Figure 1 indicates that in the determination of in vivo stability of ${ }^{99 \mathrm{~m}} \mathrm{Tc}$ labeled RBCs approximately $89 \%$ was bound after $2 \mathrm{hr}$ in situ, with approximately $87 \%$ bound after $4 \mathrm{hr}$. These results verified stability of the radiolabeled cells for a time period far in excess of the time required to complete the study when compared to the 15 min equilibrium sample $(90.5 \%)$.

Figure 2 compares the results of ${ }^{99 \mathrm{~m}} \mathrm{Tc}$ radiolabeled $\mathrm{RBC}$ binding with the ${ }^{51} \mathrm{Cr}$ labeling method. Analysis of the means from the 13 dogs studied revealed that there was no statistical difference $(P<0.01)$ between the mean $\mathrm{RBC}$ blood volume of the ${ }^{51} \mathrm{Cr}$ determinations or mean percentage of binding from that of the ${ }^{99 \mathrm{~m}} \mathrm{Tc} \mathrm{RBC}$ volumes. It was noted that the proposed procedure utilizing ${ }^{99 \mathrm{~m}} \mathrm{Tc}$ as the radionuclide for the labeling of $\mathrm{RBCs}$ produced a higher mean percentage of binding (approximately $6 \%$ ) than does the well-accepted standard method utilizing ${ }^{51} \mathrm{Cr}$ (Fig. 2).

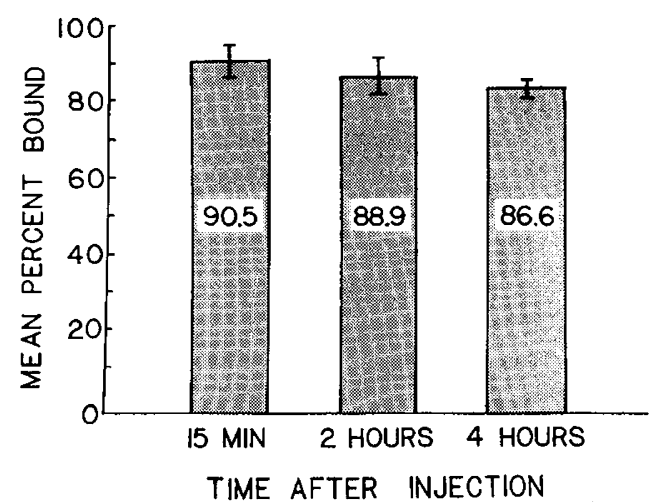

Fig. 1. Determination of in vivo stability of technetium-99m-labeled $\mathrm{RBC}$, with time, in a canine model. Data are expressed as mean \pm standard deviation.

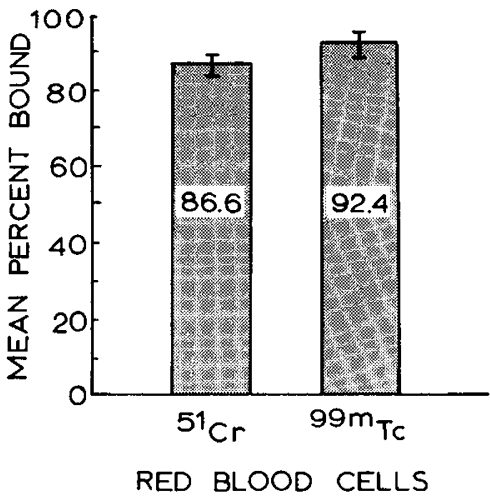

Fig. 2. Comparison of the labeling efficiency of chromium-51 and technetium-99m RBC. Data are expressed as mean \pm standard deviation.

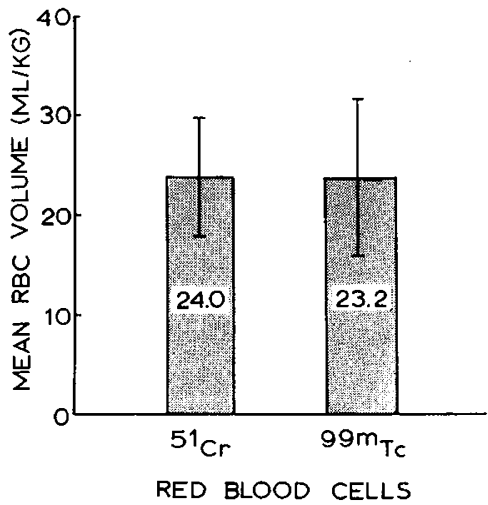

Fig. 3. Comparison of $\mathrm{RBC}$ volume in an ovine model as determined by chromium- 51 and technetium- $99 \mathrm{~m}$ labeled RBCs. Data are expressed as mean \pm standard deviation.

The newborn lamb data, as seen in Figure 3, compared the $\mathrm{RBC}$ volume determinations of the two radionuclide labeling procedures. Statistical analysis of the means revealed that there was no difference $(P<0.01)$ in the blood volumes as measured by the ${ }^{99 \mathrm{~m}} \mathrm{Tc}$ or ${ }^{51} \mathrm{Cr}$ techniques.

The absorbed radiation dose to an average $3.1-\mathrm{kg}$ newborn and to the $70-\mathrm{kg}$ standard man from a 5- and a $30-\mu \mathrm{Ci}$ dose, respectively, of injected ${ }^{99 \mathrm{~m}} \mathrm{Tc}$ RBCs was calculated for both total body and for the spleen. These calculations were made according to the MIRD Committee's Pamphlet No. 11 (8). The results are summarized in Table 1, comparing the absorbed dose delivered by the two radionuclides. 
Table 1. Comparison of radiation dose from chromium-51 and technetium-99m-labeled RBC

\begin{tabular}{|c|c|c|c|c|}
\hline \multirow[b]{3}{*}{ RBC label } & \multicolumn{4}{|c|}{ Absorbed dose (mrad) } \\
\hline & \multicolumn{2}{|c|}{ Spleen } & \multicolumn{2}{|c|}{ Total body } \\
\hline & Newborn ${ }^{1}$ & $\begin{array}{c}\text { Standard } \\
\operatorname{man}^{2}\end{array}$ & Newborn ${ }^{1}$ & $\begin{array}{c}\text { Standard } \\
\operatorname{man}^{2}\end{array}$ \\
\hline${ }^{51} \mathrm{Cr}$ & 340.0 & 120.0 & 30.0 & 12.3 \\
\hline${ }^{99 \mathrm{~m}} \mathrm{Tc}$ & 4.4 & 4.3 & 0.9 & 0.5 \\
\hline
\end{tabular}

${ }^{1} 5 \mu \mathrm{Ci}$ dose per $3.1 \mathrm{~kg}$.

${ }^{2} 30 \mu \mathrm{Ci}$ dose per $70 \mathrm{~kg}$.

\section{DISCUSSION}

Traditionally, the assumption has been made that measures of large vessel peripheral hematocrit, or similar ratio-dependent measures such as hemoglobin and total RBC count, were representative "averages" for these parameters in the total body. Hahn et al. (3) demonstrated in 1942 that this presumption was not true. Using four independent methods, they found that a 20 to $25 \%$ error existed in measured blood volumes which used these parameters. They were further able to show that measurements of hematocrit from a peripheral large vessel could not be used to measure the whole body hematocrit. Although Hahn's theoretical reasoning on plasma stagnation remained to be proven, the contention that large vessel values differed from small vessel hematocrit was reluctantly accepted.

In 1950, Sterling and Gray (9) introduced the use of an ionic hexavalent chromium (as sodium chromate) technique using radioactive ${ }^{51} \mathrm{Cr}$. The in vitro incubation of this radionuclide with $\mathrm{RBCs}$ produced a superior technique for the direct measure of $\mathrm{RBC}$ volume by radionuclide dilution techniques. Reeve (7) further elucidated the errors associated with volume-dilution techniques. He particularly pointed out the dangers of cross-calculation of the companion compartment from a direct determination of the other, such as RBC volume from determined plasma volume using large vessel hematocrit. Thus, the medical community has been counseled by a body of scientific evidence that dependence upon ratio examinations provides significant pitfalls for the unwary.

Based upon this information, it would appear that in contemporary medical practice such cross-calculation techniques should be avoided. Although this evidence is now some four decades old, these errors are continually being propagated by cross-calculations dependent upon hematocrit values. The answer to this dilemma lies in the direct assessment of both compartments of the vascular system. Thus, to accurately determine the whole-body blood volume, an accurate measurement of plasma volume and red cell volume must be independently determined.

Although the plasma compartment can be assessed by standard volume dilution techniques, usually using an iodinated human serum albumin technique, this paper describes a newer, modified procedure for the radiolabeling of $\mathrm{RBCs}$, which allows direct determination of this critically important compartment. The RBCs are prepared utilizing the short half-life radiopharmaceutical sodium pertechnetate $\left({ }^{99 \mathrm{~m}} \mathrm{Tc}\right)$.
Table 2. Physical characteristics of subject radionuclides

\begin{tabular}{cccc}
\hline & \multicolumn{3}{c}{$\begin{array}{c}\text { Countable pho- } \\
\text { tons/nuclear } \\
\text { transformation } \\
(\%)\end{array}$} \\
\hline${ }^{51} \mathrm{Cr}$ & 28 & 9 & Energy (keV) \\
${ }^{99 \mathrm{~m}} \mathrm{Tc}$ & 6 & 90 & 320 \\
\hline
\end{tabular}

This labeling procedure has been shown to provide an accurate and convenient method for measuring $\mathrm{RBC}$ volume. The method can be completed aseptically in a closed system and lends itself to the small volumes required for $\mathrm{RBC}$ volume assessment in neonate and preterm infants. When compared to the standard technique utilizing ${ }^{51} \mathrm{Cr}$, this technique has been shown to be comparable. Both in vitro and in vivo stability were shown to be as good as, and in some cases better than, chromium-labeled RBCs.

This procedure offers several advantages over the standard technique for the determination of $\mathrm{RBC}$ volume. To wit, the much shorter half-life of ${ }^{99 \mathrm{~m}} \mathrm{Tc}$, when compared to ${ }^{51} \mathrm{Cr}$, allows for an increase in the amount of administered radioactivity, thus increasing counting statistics (Table 2). With the shorter half-life, the $\mathrm{RBC}$ volume determination may be repeated at shorter intervals, many times a necessity in the acutely ill neonate, and a dramatic reduction in the absorbed radiation dose has been achieved. There are no contraindications to this study, and the physical decay advantages of ${ }^{99 \mathrm{~m}} \mathrm{Tc}$ suggest that this procedure should be utilized preferentially over the ${ }^{51} \mathrm{Cr}$ technique for the labeling of erythrocytes, particularly in this age group.

\section{REFERENCES AND NOTES}

1. Eckelman, W., Richards, P., Hauser, W., and Atkins, H.: Technetium-labeled red blood cells. J. Nucl. Med., 12: 22 (1971).

2. Faxelius, G., Raye, J., Gutberlet, R., Swanstrom, S., Tsiantos, A., Dolanski, E., Dehan, M., Dyer, N., Lindstrom, D., Brill, A., and Stahlman, M.: Red cell volume measurements and acute blood loss in high-risk newborn infants. J. Pediatr., 90: 273 (1977)

3. Hahn, P., Ross, J., Bale, W., Balfour, W. M., and Whipple, G. H.: Red cell and plasma volumes (circulating and total) as determined by radioiron and by dye. J. Exp. Med., 75: 221 (1942).

4. Keys, J., Jr., Carey, J., Moses, D., and Beierwalters, W.: Manual of nuclear medicine procedures, Ed. 2 (CRC Press, Cleveland, OH, 1973).

5. Korubin, V., Maisey, M., and McIntyre, P.: Evaluation of technetium-labeled red cells for determination of red cell volume in man. J. Nucl. Med., 13: 760 (1972).

6. Pavel, D., Zimmer, A., and Patterson, V.: In vivo labeling of red blood cells with ${ }^{99 \mathrm{~m}}$ Tc: a new approach to blood pool visualization. J. Nucl. Med., 18: 305 (1977).

7. Reeve, E.: Use of radioactive phosphorus for the measurement of red cell and blood volume. Br. Med. Bull., 8: 181 (1952).

8. Snyder, W., Ford, M., Warner, G., and Watson, S.: "S" absorbed dose per unit cumulated activity for selected radionuclides and organs. (NM/MIRD Pamphlet No. 11, Society of Nuclear Medicine, New York, 1975).

9. Sterling, K., and Gray, F.: Radiochromium determination of circulating red cell volume. J. Clin. Invest., 29: 1614 (1950).

10. Subramanian, G.: ${ }^{99 m}$ Tc labeled radiodiagnostic agents. A compilation of current procedures. (Division of Nuclear Medicine, Department of Radiology, Upstate Medical Center, Syracuse, NY, 1974).

11. Requests for reprints should be addressed to: Dr. Merton A. Quaefe, Division of Nuclear Medicine, Department of Radiology, University of Nebraska Medical Center, 42nd and Dewey Ave., Omaha, NE 68105 (USA).

12. Received for publication June 18,1980

13. Accepted for publication September 3, 1980. 